\section{Plantar pitted keratolysis: a study from non-risk groups}

\section{Asli Feride Kaptanoglu, ${ }^{1}$ Ozlem Yuksel, ${ }^{2}$ Selcuk Ozyurt ${ }^{3}$}

${ }^{1}$ Near East University, Lefkosa-North Cyprus, Turkey; ${ }^{2}$ Bayindir Hospital Kavaklidere, Ankara, Turkey; ${ }^{3}$ zmir Ataturk Research and Education Hospital, İzmir,Turkey

\begin{abstract}
Pitted keratolysis is an acquired, superficial bacterial infection of the skin which is characterized by typical malodor and pits in the hyperkeratotic areas of the soles. It is more common in barefooted people in tropical areas, or those who have to wear occlusive shoes, such as soldiers, sailors and athletes. In this study, we evaluated 41 patients who had been diagnosed with plantar pitted keratolysis. The patients were of high socioeconomic status, were office-workers, and most had a university degree. Malodor and plantar hyperhydrosis were the most frequently reported symptoms. The weight-bearing metatarsal parts of the feet were those most affected. Almost half the women in the study gave a history of regular pedicure and foot care in a spa salon. Mean treatment duration was 19 days. All patients were informed about the etiology of the disease, predisposing factors and preventive methods. Recurrences were observed in only $17 \%$ of patients during the one year follow-up period. This study emphasizes that even malodorous feet among non-risk city dwellers may be a sign of plantar pitted keratolysis. A study of the real incidence of the disease in a large population-based series is needed.
\end{abstract}

\section{Introduction}

Pitted keratolysis is an acquired, superficial bacterial infection of the skin. The characteristic features of the diseaseare multiple crateriform pits (usually in the weight-bearing areas of the soles), maceration (mostly because of hyperhydrosis), a typical unpleasant smell, and sliminess of the feet. Pitted keratolysis has a worldwide distribution, but the disease is more common among barefooted people living in tropical regions. No race or sex predilection has been reported. ${ }^{1-3}$ In this study, we documented clinical and demographic data of 41 plantar-pitted keratolysis patients who were admitted to a private hospital in Ankara, Turkey.

\section{Materials and Methods}

The study included all patients diagnosed with plantar-pitted keratolysis in a 2 -year period among the patients of the dermatology department of a private hospital in Ankara. An unproblematic clinical diagnosis of pitted keratolysis was made in almost all of the 41 patients with the help of the unique malodor of the disease. In 11 of the patients, Gram's staining was performed to show the rod like organisms confirming the diagnosis of pitted keratolysis. However, mycotic investigations and wood light examination were carried out in every patient to exclude tinea pedis and erythrasma. In some suspected patients, bacteriological cultures or histopathological examinations were carried out to exclude other bacteriological infections and some keratodermas. Patients with a diagnosis other than pitted keratolysis were excluded from the study, but 4 of the patients who concomitantly had both tinea pedis and pitted keratolysis were included. Patients were investigated with a special emphasis on the triggering factors and the results were recorded.

\section{Results}

Of the 41 pitted keratolysis patients included in this study, 24 were male (58.6\%) and 17 were female (41.4\%). Patients were between 18-56 years of age (mean 38.95 years). Most of the patients were office workers of a high socioeconomic status and had a university degree $(\mathrm{n}=24,58.6 \%)$. Thirteen patients (31.7\%) had a high school degree and reported prolonged use of occlusive footwear for work. Three patients were students (7.3\%) and one was not educated (2.4\%).

Patients mostly complained about malodor $(\mathrm{n}=41,100 \%)$, wet feet $(\mathrm{n}=27,66 \%)$, sliminess of the feet $(\mathrm{n}=11,26.8 \%)$, pain and burning sensation in the feet $(n=11,26.8 \%)$ and pruritus $(n=1,2.4 \%)$. None of the patients reported a seasonal change in their condition. None of the patients reported involvement of the palms of their hands. Weight-bearing metatarsal regions of the feet were most commonly involved areas $(\mathrm{n}=39,95.1 \%)$.

Physical examination mostly revealed malodor (100\%) and hyperkeratosis (58.6\%) of the soles. Maceration due to hyperhydrosis was found in $31.7 \%$ of patients, whereas fissures and erythema were seen in $14.6 \%$ and $2.4 \%$ of cases, respectively.

Four of the patients had concomitant tinea pedis (9.7\%). Plantar warts and corns were observed in $7.3 \%$ and $2.4 \%$ of cases, respectively. No corynebacterial triad (pitted keratolysis, erythrasma and trichomycosis) was seen in
Correspondence: Asli Feride Kaptanoglu, Near East University, Ankara, Turkey.

E-mail: dr.aslikaptanoglu@gmail.com

Key words: plantar pitted keratolysis; foot odour; risk groups.

Received for publication: 25 July 2011.

Revision received: 21 November 2011.

Accepted for publication: 1 December 2011.

This work is licensed under a Creative Commons Attribution NonCommercial 3.0 License (CC BYNC 3.0).

CC Copyright A.F. Kaptanoglu et al., 2012

Licensee PAGEPress srl, Italy

Dermatology Reports 2012; 4:e4

doi:10.4081/dr.2012.e4

any of the patients in the present study.

As there is no system for scoring the severity of plantar pitted keratolysis, treatment was planned according to the clinical appearence of lesions, depending on the anatomic extension of lesions, the hyperkeratosis and depth of the pits. Only topical treatment with $4 \%$ erythromycin gel was applied in 9 patients (21.9\%) who had malodor and slight pits. Patients $(\mathrm{n}=32,78.1 \%)$ with more severe clinical appearance (malodor, hyperkeratosis deep pitted lesions and maceration) needed both systemic and topical treatment. Roxytromycine $300 \mathrm{mg} /$ day was used as a systemic antibiotic. Patients ( $n=19,46.4 \%)$ who had malodor, hyperkeratosis and deeper pitted lesions were treated with $10 \%$ salicylic acid, including creams in addition to erythromycine gel. In patients with severe maceration, $0.01 \%$ KMNO4 solution was also used for its astringent and drying properties (Table 1). Patients were controlled weekly and topical treatments were continued until symptoms had completely disappeared. All patients reported strict adherence to treatment and kept their checkup appointments. Treatment lasted between one and eight weeks (mean 19 days).

During the treatment period, patients used cotton socks and followed suggestions for changes in their daily habits. They did not wear the same shoes for two consecutive days.

During the 1-year follow up, recurrence was observed in 7 (17\%) patients. Time to recurrence was 4-12 months. The common feature of these patients was the highly hyperkeratotic tissue of the sole; one was in severe depression and one was deeply immunosupressed.

\section{Discussion}

Pitted keratolysis is a skin disorder charac- 
Table 1. Treatment modalities according to clinical appearance.

\begin{tabular}{|c|c|c|c|}
\hline Symptom & $\mathbf{N}(\%)$ & Topical treatment & Systemic treatment \\
\hline Malodor-pits & $9(21.9)$ & Erythromycine gel & - \\
\hline Malodor-hyperkeratosis-deeper pits & $\begin{array}{c}19(46.4) \\
10 \% \text { salicylic acid cream }\end{array}$ & Erythromycine gel & $\begin{array}{l}\text { Roxytromycine } \\
300 \text { mg/day }\end{array}$ \\
\hline Malodor-hyperkeratosis-deeper pits-maceration & $13(31.7)$ & $\begin{array}{c}\text { Erythromycine gel } \\
\text { 10\% salicylic acid cream } \\
0.01 \% \text { KMNO4 Solution }\end{array}$ & $\begin{array}{l}\text { Roxytromycine } \\
300 \mathrm{mg} / \text { day }\end{array}$ \\
\hline
\end{tabular}

terized by crateriform pits that primarily affect the pressure-bearing parts of the plantar surfaces of the feet and occasionally the palms of the hands. The manifestations are due to a superficial cutaneous bacterial infection. The causavite agents are corynebacterium species, kytococus sedentarius and dermatophilus congolensis. ${ }^{2-5}$ Pitted keratolysis was first reported by Castellani in a Ceylonese patient in 1910, and was confirmed as a unique separate clinical entity in the 1930s. The current name, plantar pitted keratolysis, was used to define the clinical presentation. ${ }^{1}$

Diagnosis can easily be made by means of visual examination and recognition of the characteristic odor. ${ }^{2}$ In our study, patients were aged between $18-56$ years (mean 38.95 years), which correlated with the other reports. ${ }^{6}$ Pitted keratolysis is observed in males more than females. $^{6-9}$ In our study, the male to female ratio was 6:4, showing an almost equal predilection. Pitted keratolysis is reported to be more common among barefooted laborers/ farmers, sailors, soldiers and industrial workers wearing occluded wet shoes for prolonged periods. ${ }^{1}$ Ramsey reported pitted keratolysis as a common infection of active feet as sporting activity makes the feet hot and wet. ${ }^{10}$ In our study, there were no barefoot laborers, farmers, sailors or soldiers. Most of our cases were office workers and well-educated people who take care of their personal hygiene. Prolonged use of footwear could be the common factor in these subjects. Interestingly, more than the half of the female patients (58.8\%) had a history of regular pedicure and foot care in a spa salon. Moisture and inappropriate hygiene may be the predisposing factors in such patients.

Pitted keratolysis is usually asymptomatic but patients may complain of hyperhydrosis, sliminess, malodor and occasionally soreness, itching and pain while walking. ${ }^{11,12}$ In our study, malodor (100\%) was the most commonly reported symptom. In one series, Naik and Singh reported malodor in $70 \%$ of patients. 6 Malodor could be the most important indication of disease because of its negative impact in office-working conditions. Pain and a burning sensation were reported by almost a quarter of the patients (26.8\%). Sliminess of the skin was also a common complaint (26.8\%).
Pruritus was present in only one patient (2.4\%).

Interdigital intertrigo and paronychia may coexist with pitted keratolysis but these are reported to have no influence on the onset or course of the disease. ${ }^{11}$ Associated dermatophyte infections were also evident in $17.1 \%$ of our patients. Associated plantar warts and corn was observed in 7.3 and $2.4 \%$ of the cases, respectively. Corynebacterial triad (pitted keratolysis, erythrasma and trichomycosis ) was not seen in any of the patients in the present study. The other associated diseases were diabetes mellitus (9.75\%), depression (2.4\%), and immunosuppression (7.31\%) due to chemotherapy for ovarian carcinoma, and interferon treatment for hepatitis $\mathrm{B}$ and $\mathrm{C}$. The predisposing factors are known to be a humid climate, poor hygiene, hyperhydrosis, obesity, diabetes, advanced age and immunocompromised host. ${ }^{2}$ In contrast with the literature, the city where the study took place does not have a hot and humid climate and patients showed a good standard of personal hygene. However, the associated disorders, such as diabetes or immunosuppression, were correlated with the other reports.

Pitted keratolysis has been reported to have an excellent prognosis; effective treatment clears both the lesions and the odor in 3-4 weeks time. Topical antibiotics are reported to be effective, easy to use and acceptable by the patients. Recommendations include twicedaily application of erythromycin solution or gel, $1 \%$ clindamycin hydrochloride solution, fusidic acid cream and mupirocin cream. Use of systemic antiobiotic may shorten the treatment period. ${ }^{1-3}$ Koc et al. reported topically applied clindamycin and erytromycin to be both safe and effective. ${ }^{13}$ In a case of Ertam $e t$ $a l$. , three weeks of oral erythromycin treatment was reported to be effective. ${ }^{14}$ In our study, only topical treatments were applied in 9 cases whereas 32 patients needed both topical and systemic treatments. Treatment duration was 1-8 weeks (mean 19 days) which was almost twice that reported by Koc et al. ${ }^{13}$

During the follow-up period, recurrence was observed in 7 (17\%) of the patients after one year. Most of the patients (83\%) had no recurrence after one year. This might be because of the increased awareness in avoiding the pre- disposing factors, as well as applying the treatments correctly. The common feature of the 7 recurrent cases was the highly hyperkeratotic tissue of the soles. Patients should be warned about the importance of plantar hyperkeratosis in disease development, as under suitable conditions, like prolonged occlusion, hyperhydrosis, and increased skin surface $\mathrm{pH}$, bacterias that cause the disease may proliferate and produce proteinases which in turn destroy the hyperkeratotic stratum corneum, creating pits and causing malodor. Maintenance treatment may be suggested to these high-risk patients. Preventive measures, such as avoiding occlusive footwear, not sharing shoes or towels with others, using absorbent cotton socks, and drying feet properly after washing should be recommended. Most of our patients maintained a good standard of personal hygiene and were careful about using shoes, socks or towels but they all prolonged use of occlusive footwear.

\section{Conclusions}

Plantar pitted keratolysis is a disease mostly affecting the soles of the feet. It is a bacterial infection and usually occurs because of prolonged use of occlusive footwear. Although a lot of people have smelly feet there are not many reports about the real incidence of plantar pitted keratolysis. The only reports concern highrisk groups. Our study showed that the incidence of pitted keratolysis might be more common than suspected. Instead of seeking medical help, people with foot odor might be using over the counter products which mostly contain anti-fungals and anti-perspirants or sometimes ointments which may aggrevate maceration.

\section{References}

1. Singh G, Naik CL. Pitted keratolysis. Indian J Dermatol Venereol Leprol 2005; 71:213-15.

2. Martin AG, Kobayashi GS. Bacterial diseases with cutaneous involvement. In: Freedberg IM, Eisen AZ, Wolff $\mathrm{K}$, et al. Dermatology in general medicine. New 
York: McGraw Hill Inc, 5 th edi; 1999. pp 2203-2204.

3. English JC. Pitted keratolysis. eMedicine J 2003;11:1-7.

4. Woodgyer AJ, Baxter M, Rush-Munro FM. Isolation of Dermatophilus congolensis from two New Zealand cases of pitted keratolysis. Aust J Dermatol 1985;26:29-35.

5. LongshawCM, Wright JD, Farrel AM, Holland KT. Kytococcus sedentarius the organism associated with pitted keratolysis,produces keratin-degrading enzymes. J Appl Microbiol 2002;93:810-6.

6. Naik CL, Singh G. Clinico epidemiological study of pitted keratolysis. Ind J Dermatol 2007;52:35-8.

7. Schissel DJ. Aydelotte J, Keller R. Road rash with a rotten odor. Mil Med 1999;164:65-7.

8. Gill KA, Buckels LJ. Pitted keratolysis. Arch Dermatol 1968;98:7-11.

9. Morse JM. When a patient presents with malodorus, macerated feet. Podiatry Today 2008;12:26-32.

10. Ramsey ML. Pitted keratolysis. A common infection of active feet. Phys Sport Med 1996;24:1-4.

11. Takama H, Tamada Y, Yano K, et al. Pitted keratolysis. Clinical manifestations in 53 cases. Br J Dermatol 1997;137:282-5.

12. Narayani K, Gopinathan T, Ipe PT. Pitted keratolysis. Indıan J Dermatol Venereol Leprol 1981;47:151-4.

13. Koc E, Arca E, Akar A, Gür AR. Comparison of topical Clindamycine solution with erytromycin gel treatment in pitted keratolysis. Dermatose 2004;4:37-41.

14. Ertam I, Aytimur D, Yuksel SE. Isolation of Kytococcus sedentarius from a case of pitted keratolysis. Ege Tip Dergisi 2005; 44:117-8. 